\title{
The Discovery of Oligoclonal Bands: A 50-Year Anniversary
}

\author{
Trygve Holmøy
}

Institute of Immunology, Faculty of Medicine, University of Oslo, Oslo University Hospital Rikshospitalet and Department of Neurology, Oslo University Hospital Ullevål, Oslo, Norway

\section{Key Words}

History of medicine - Cerebrospinal fluid - Electrophoresis • Multiple sclerosis

\begin{abstract}
The discovery of the oligoclonal IgG bands (OCB) in the cerebrospinal fluid (CSF) was a major step forward in the understanding of multiple sclerosis (MS) and other inflammatory diseases of the central nervous system. Separation of IgG molecules produced by different B cell clones was not possible until agar electrophoresis was invented in 1950. The key observation that led to the discovery of OCB can be dated back to 1959, when Karcher, van Sande and Lowenthal reported that agar electrophoresis subdivided CSF $\gamma$-globulins from a patient with subacute sclerosing panencephalitis into several individual fractions, which were distinguishable with densitometry. OCB were detected in CSF from patients with trypanosomiasis, neurosyphilis and MS by the same research group in 1960 . The discovery of OCB was preceded by the detection of intrathecal IgG synthesis with Tiselilus' moving boundary electrophoresis by Kabat in 1942. This method did not allow separation of IgG molecules produced by different $B$ cell clones, and it is therefore a misconception that Kabat discovered the OCB. The discovery of OCB led to the still prevailing concept that MS is mediated by clonally expanded lymphocytes, and provided the basis for modern diagnostic procedures in MS.
\end{abstract}

Copyright $\odot 2009$ S. Karger AG, Base

\section{Introduction}

Intrathecally synthesized oligoclonal IgG bands (OCB) in cerebrospinal fluid (CSF) are the immunological hallmark of multiple sclerosis (MS), and can also be seen in infections and other inflammatory disorders of the central nervous system (CNS). The discovery of the OCB can be traced back to 1959. It is often confused with the detection of intrathecal IgG synthesis, which was achieved in 1942 [1]. Both these endeavours share a common theme, as they are both based on skilful applications of evolving electrophoretic techniques. However, whereas the discovery of intrathecal synthesis of IgG is widely acknowledged, the pioneers who discovered the OCB are often neglected when the history of MS and CSF research is told $[2,3]$. The aim of this non-exhaustive historical note is to provide a brief historical background about the discovery and early exploration of the OCB, and to draw attention to some of those who contributed.

\section{Before Electrophoresis}

Modern biochemical analysis of human CSF proteins is usually dated back to the discovery of intrathecal synthesis of IgG in 1942 by Elvin Kabat [4]. Before that, the colloidal gold activity method was prevailing for analysis of CSF proteins [5]. The basis for the colloidal gold activity method was that proteins, due to their physicochemi-

\section{KARGER \\ Fax +4161306 1234 E-Mail karger@karger.ch} www.karger.com
(C) 2009 S. Karger AG, Basel 0014-3022/09/0625-0311\$26.00/0

Accessible online at: www.karger.com/ene
Trygve Holmøy, MD, $\mathrm{PhD}$

Institute of Immunology

Oslo University Hospital Rikshospitalet

NO-0027 Oslo (Norway)

Tel. +47 2307 3500, Fax +47 2307 3510, E-Mail trygve.holmoy@rr-research.no 
cal properties, can serve as either flocculants or stabilizers for gold colloids. It did not allow quantification of the globulin fraction, but depended on the relative proportion of albumin to $\gamma$-globulin. The colloidal gold method was invented in 1912 by Carl Lange, an assistant physician at the Rudolf Virchow Hospital in Berlin, as a diagnostic test for neurosyphilis [6]. It was indeed most sensitive in patients with neurosyphilis, but some MS patients also displayed an abnormal protein precipitation pattern of CSF proteins, commonly denoted a paretic Lange curve [7]. Although improved by controlling the $\mathrm{pH}$ and the size of the gold particles [8], the sensitivity and specificity of the colloidal gold activity method in MS were low and varied greatly between laboratories [9].

\section{Detection of Intrathecal Synthesis of IgG}

In 1930 the Noble Prize laureate Arne Tiselius published his thesis on moving boundary electrophoresis [10]. By this method, sharp electrophoretic boundaries of ionized molecules could be obtained, and this allowed Tiselius to describe moving boundaries corresponding to albumin, $\alpha$-, $\beta$ - and $\gamma$-globulin in serum [11]. The biochemist Elvin Kabat learned moving boundary electrophoresis from Tiselius in Uppsala [11]. Kabat returned to Columbia University in New York in 1941, and in 1942 he used the Tiselius method to demonstrate that colloidal gold activity was associated with the $\gamma$-globulin fraction in CSF [1]. The most impressive increase in $\gamma$-globulin in CSF was noted in patients with neurosyphilis. One of the five MS patients studied displayed a high concentration of $\gamma$-globulin in CSF, but this patient also had a high concentration of $\gamma$-globulin in serum. The conclusion that 'some formation of gamma globulin could take place within the tissues of the central nervous system and be poured into the cerebrospinal fluid' [1] was therefore based on observations in neurosyphilis and not in MS.

Kabat initially used as much as $70 \mathrm{ml} \mathrm{CSF}$ which was concentrated to $2 \mathrm{ml}$ (up to $80 \mathrm{ml} \mathrm{CSF}$ was collected from each patient) [1]. This precluded the use of moving boundary electrophoresis in clinical practice. By using a quantitative precipitin method, Kabat later reduced the quantity required for estimation of albumin and $\gamma$-globulin to less than $7 \mathrm{ml}[9]$. He was also able to determine normal values for albumin and $\gamma$-globulin in CSF and to demonstrate elevated CSF $\gamma$-globulin in 8 of 14 patients with MS and in 15 of 16 patients with neurosyphilis.

In the late 1950s, Frick and Scheid-Seydel used ${ }^{131}$ I-labeled $\gamma$-globulin and albumin to demonstrate that a frac- tion of the $\gamma$-globulin in CSF from MS patients was not derived from serum $[12,13]$. They also showed that all albumin in the CSF was derived from serum [14], which is the basis for the IgG index. Wallace Tourtellotte later demonstrated that there is a positive correlation between the concentration of $\operatorname{IgG}$, but not of albumin, in MS brains and in CSF $[15,16]$. These findings confirmed that $\gamma$-globulin can be synthesized within the CNS, but not its oligoclonal pattern.

\section{Qualitative Methods}

The basis for the variable electrophoretic mobility of OCB is that the amino acid sequences vary between the constant regions of different IgG subclasses and also between the variable regions (idiotypes) of IgG molecules produced by different $\mathrm{B}$ cell clones. Differences in glycosylation and post-translational modifications may add further heterogeneity, and IgG molecules of different clonal origin therefore differ slightly in size and charge. Although Tiselius' moving boundary electrophoresis allowed accurate measurement of the mobilities of groups of proteins, it did not allow complete separation of the components of a mixture [10]. The resolution was therefore too low to separate IgG molecules produced by different $B$ cell clones. In order to obtain sufficient resolution for this purpose, electrophoresis had to be carried out in a support medium. Thus, it was the invention of agar gel electrophoresis, with its superior resolving power compared to other electrophoretic methods available at that time [17], that set the scene for the discovery of the OCB.

\section{The Discovery of the OCB}

Electrophoretic separation of CSF proteins with different electrophoretic techniques was performed in the late 1950s at the Laboratory of Biochemistry at the Bunge Institute in Antwerp, Belgium [18, 19]. Paper electrophoresis suggested that $\gamma$-globulins in the CSF from some patients with African trypanosomiasis were differentially glycosylated [20], but the resolution was still too low to separate individual IgG subfractions. In 1959, Denise Karcher reported that agar electrophoresis was superior to paper elecrophoresis for separation of $\gamma$-globulins in CSF [21]. In this report, individual IgG subfractions were not directly visible by inspection of the agar gel. However, densitometry revealed that the IgG fraction in the CSF from a patient with subacute sclerosing panencephalitis 

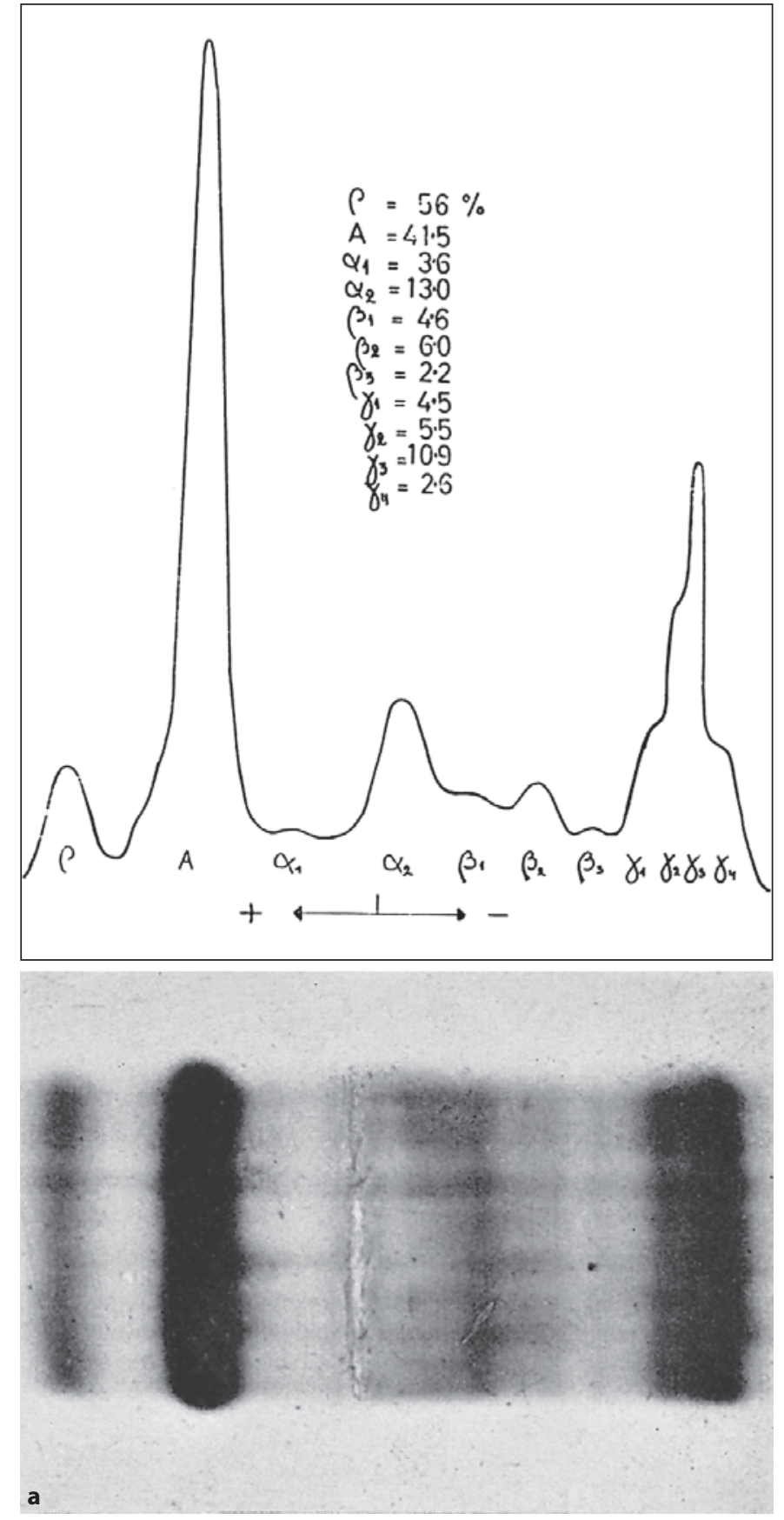

Fig. 1. The first demonstration of different mobilities of $\gamma$-globulin subfractions in CSF. a Densitometry (upper panel) of agar electrophoresis (lower panel) of concentrated CSF from a patient with subacute sclerosing panencephalitis displayes four subfractions of

(which was known as subacute sclerosing leukoencephalitis at that time) was subdivided into 4 subfractions denoted $\gamma_{1-4}$ (fig. 1). This picture is probably as close to the birth of the OCB as we can get, and prompted the conclusion that: 'Electrophoresis in agar gel reveals in the CSF

Discovery of Oligoclonal Bands

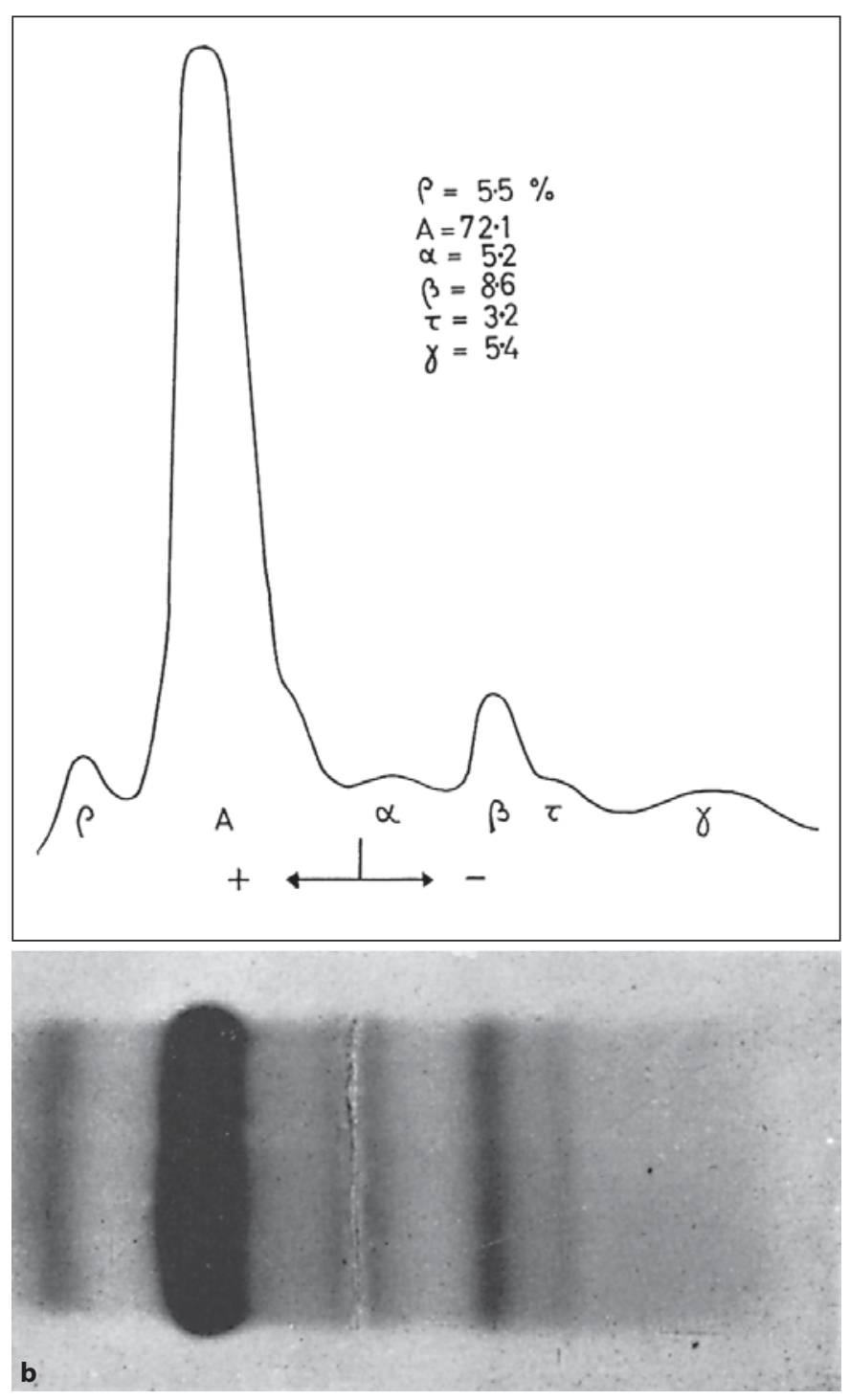

$\gamma$-globulin $\left(\gamma_{1-4}\right)$. b Densitometry of agar electrophoresis of normal CSF. Reproduced from Karcher et al. [21] with permission from Wiley.

of subacute sclerosing leukoencephalitis patients an increase in the $\gamma$-globulins, which can be subdivided into several individual fractions. These subfractions which differ in mobility may probably also differ in chemical composition' [21]. 


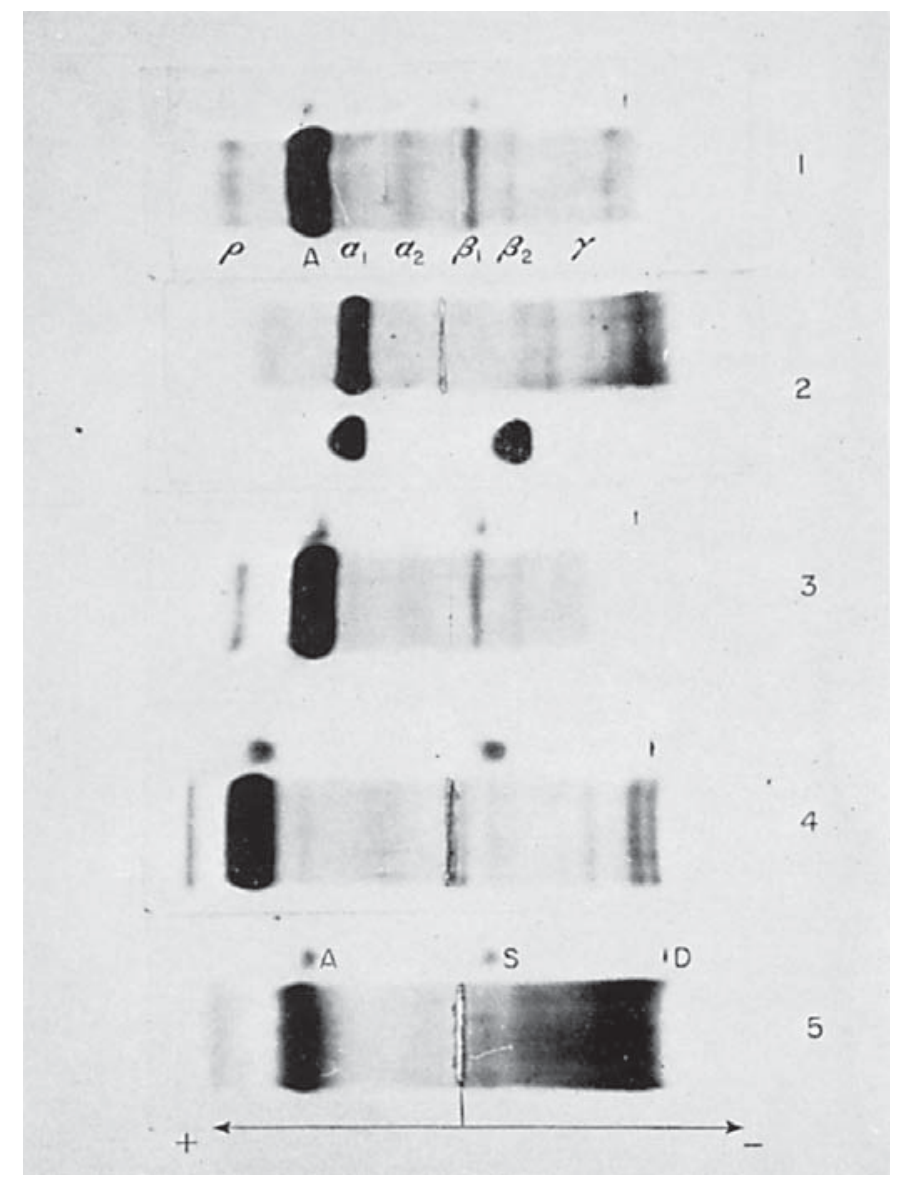

Fig. 2. The first clear visualization of OCB in CSF. The figure shows agar electrophoresis of CSF from a patient with multiple sclerosis (1), subacute sclerosing panencephalitis (2), normal control (3), neurosyphilis (4) and African trypanosomiasis (5). Distinguishable OCB in the $\gamma$-region are prominent in CSF from patient 4. Reproduced from Lowenthal et al. [22] with permission from Wiley.

The report from 1959 is rarely quoted. One reason may be that the different IgG subfractions are not recognized without the use of densitometry, and also that the concept 'oligoclonal' was not yet coined. A more famous paper published in 1960 described the electrophoretic patterns of CSF from patients with MS, subacute sclerosing leucoencephalitis, neurosyphilis and African trypanosomiasis [22]. Most of these patients had at least $1 \mathrm{IgG}$ subfraction and several patients displayed up to 6 distinguishable IgG subfractions, which were denoted $\gamma_{1-6}$. The OCB were more clearly demarcated than in the 1959 paper and could be identified without using densitometry, particularly in a patient with neurosyphilis (fig. 2). This may be the reason why the discovery of OCB is sometimes dated back to 1960 [23]. Another reason could be that the 1960 paper included patients with MS, in whom CSF OCB received greatest attention.

Armand Lowenthal himself pointed out that 1959 was the year of the discovery of the oligoclonal reaction of the CSF IgG [24]. This seems justified from the clear description of IgG subfractions with different electrophoretic mobility in the 1959 paper [21], which indeed was the breakthrough in the discovery of the OCB.

The term oligoclonal was not invented by Lowenthal; it was invented later by the neurologist Christian Laterre who worked in Louvain, Belgium [4, 25]. Together with Jorgen Clausen, one of the other pioneer neurologists who implemented electrophoresis in neuroimmunology $[26,27]$, Laterre confirmed the initial discovery of OCB and contributed strongly to its clinical implementation.

\section{Intrathecal Synthesis of OCB}

Lowenthal, van Sande and Karcher did not include serum samples in their initial reports [21,22], and it was therefore not possible to tell whether the IgG fractions appearing as OCB were produced intrathecally or elsewhere. The importance of comparing the patterns of OCB in CSF and serum in order to obtain qualitative evidence of intrathecal synthesis of IgG was particularly underscored by Laterre, who also showed that the $\gamma$-globulin fraction of normal CSF was composed of both IgG and of tissue-like proteins [28]. Hans Link demonstrated that OCB could be detected in CSF from patients who did not display quantitative evidence for intrathecal synthesis of IgG $[29,30]$. In a study of 2,043 patients, Laterre indeed demonstrated that intrathecally synthesized OCB were detectable with agar electrophoresis in $86.9 \%$ of patients with definite MS, and that this assay was more sensitive than quantitative assays in detecting intrathecal IgG synthesis [31].

\section{Concluding Remarks}

Like any other assay, agar electrophoresis has been succeeded by other assays. Isoelectric focusing, which separates proteins according to their isoelectric point and detects OCB with greater sensitivity than agar electrophoresis, was introduced in CSF analysis during the early 1970s [32, 33]. The detection of OCB in CSF by agar electrophoresis was, however, the first evidence 
suggesting that lymphocytes are clonally expanded within the CNS in MS and CNS infections, a concept which was confirmed by sequencing of immune receptor genes almost 4 decades later. Whereas the OCB have been shown to target the infectious agents in patients with CNS infections [34], the specificity and the mechanism driving the synthesis of the main fractions of the OCB in MS are still unknown. Fifty years after their discovery, the OCB therefore continue to puzzle neuroimmunologists.

\section{References}

1 Kabat EA, Moore DH, Landow H: An elctrophoretic study of the protein components in cerebrospinal fluid and their relationship to serum proteins. J Clin Invest 1942;21:571577.

2 Compston A, Lassmann, McDonald I: The laboratory science of multiple sclerosis; in Compston A, Confavreux C, Lassmann H, McDonald I, Noseworthy J, Smeith K, Wekerle H (eds): Multiple Sclerosis, ed 4. Oxford, Churchill Livingstone, 2006, pp 3945.

3 Murray JT: Multiple Sclerosis: The History of a Disease. New York, Demos Medical Publishing, 2005.

4 Thompson EJ: Brief historical review of CSF proteins; in Thompson EJ (Ed): The CSF Proteins: A Biochemical Approach. Amsterdam, Elsevier, 1988, pp 1-3.

5 Green F: The Colloidal Gold Reaction of the Cerebrospinal Fluid. Berlin, Medizin FritzDieter Söhne, 1925.

6 Harris AH, Lange C: Routine examination of cerebrospinal fluid. NY State J Med 1948;4: 418-423.

7 Hinton WA: Studies in the cerebrospinal fluid in multiple sclerosis; in Ayer JB, Foster HE (eds): Multiple Sclerosis: Association for Research in Nervous and Mental Diseases. New York, Paul B Hoeber, 1922, pp 113-121.

$>8$ Lange C, Harris AH: A citrate gold of optimal and reproducible sensitivity for use in the colloidal gold reaction. Its preparation and control. Am J Public Health Nations Health 1944;34:1087-1092.

9 Kabat EA, Glusman M, Knaub V: Quantitative estimation of the albumin and gamma globulin in normal and pathologic cerebrospinal fluid by immunochemical methods. Am J Med 1948;4:653-662.

10 Vesterberg O: History of electrophoretic methods. J Chromatogr 1989;480:3-19.

11 Putnam FW: $\alpha$-, $\beta$-, $\gamma$-globulin - Arne Tiselius and the advent of electrophoresis. Perspect Biol Med 1993;36:323-337.
12 Frick E, Scheid-Seydel L: Research with I 131-labelled $\gamma$-globulin on the problem of the origin of cerebrospinal fluid proteins. Klin Wochenschr 1960;38:1240-1243.

13 Frick E, Scheid-Seydel L: Studies with $\gamma$ globulin labeled with radioiodine on the origin of protein bodies in the cerebrospinal fluid. Klin Wochenschr 1958;36:857-863.

14 Frick E, Scheid-Seydel L: Exchange processes between plasma and cerebrospinal fluid examined with radio-iodine labeled albumin. Klin Wochenschr 1958;36:66-69.

15 Tourtellotte WW, Parker JA: Multiple sclerosis: brain immunoglobulin $\mathrm{G}$ and albumin. Nature 1967;214:683-686.

16 Tourtellotte WW, Parker JA: Multiple sclerosis: correlation between immunoglobulin $\mathrm{G}$ in cerebrospinal fluid and brain. Science 1966;154:1044-1045.

17 Righetti PG: Electrophoresis: the march of pennies, the march of dimes. J Chromatogr A 2005;1079:24-40.

18 Van Sande M, Karcher D, Lowenthal A: Electrophoretic examinations of proteins in blood and cerebrospinal fluid in multiple sclerosis patients. Acta Neurol Psychiatr Belg 1957;57:407-415.

19 Lowenthal A, Karcher D, Van Sande M: Electrophophoretic studies of central nervous system proteins. Exp Neurol 1959;1:233247.

20 Jansssens PG, Charles P, Van Sande M, Karcher D, Lowenthal A: Composition of cerebrospinal fluid in subjects with African trypanosomiasis. C R Seances Soc Biol Fil 1958;152:359-362.

21 Karcher D, Van Sande M, Lowenthal A: Micro-electrophoresis in agar gel of proteins of the cerebrospinal fluid and central nervous system. J Neurochem 1959;4:135-140.

22 Lowenthal A, van Sande M, Karcher D: The differential diagnosis of neurological diseases by fractionating electrophoretically the CSF $\gamma$-globulins. J Neurochem 1960;6:5156.

23 Poser CM: Armand Lowenthal. Orbituary. Resuscitation 2002;52:225-226.

24 Lowenthal A: Foreword; in Thompson EJ (ed): The CSF Proteins: A Biochemical Approach. Amsterdam, Elsevier, 1988.
25 Laterre EC, Heremans JF, Carbonara A: Immunological comparison of some proteins found in cerebrospinal fluid, urine and extracts from brain and kidney. Clin Chim Acta 1964;10:197-209.

26 Clausen J, Munker T: Transferrin in normal cerebrospinal fluid. Nature 1961;189:60-61.

27 Clausen J, Matzke J, Gerhardt W: Agar-gel micro-electrophoresis of the proteins in the cerebrospinal fluid from normal and pathological findings. Acta Neurol Scand 1964;40: 49-56.

28 Laterre EC: Agar gel electrophoresis of cerebrospinal fluid proteins. Semiology of the $\gamma$ zone. Acta Neurol Psychiatr Belg 1966;66: 289-304.

29 Link H: Qualitative changes in immunoglobulin G in multiple sclerosis-cerebrospinal fluid. Acta Neurol Scand 1967;43:180.

30 Link H: Immunoglobulin G and low molecular weight proteins in human cerebrospinal fluid. Chemical and immunological characterisation with special reference to multiple sclerosis. Acta Neurol Scand 1967;43:1-136.

-31 Laterre EC, Callewaert A, Heremans JF, Sfaello Z: Electrophoretic morphology of gamma globulins in cerebrospinal fluid of multiple sclerosis and other diseases of the nervous system. Neurology 1970;20:982990

32 Delmotte P: Gel isoelectric focusing of cerebrospinal fluid proteins: a potential diagnostic tool. Z Klin Chem Klin Biochem 1971;9: 334-336.

33 Kjellin KG, Vesterberg O: Thin layer isoelectric focusing of cerebrospinal fluid proteins. A preliminary report with special reference to the diagnostic significance in multiple sclerosis. Acta Neurol Scand 1972;51:379380

34 Vandvik B, Norrby E: Oligoclonal IgG antibody response in the central nervous system to different measles virus antigens in subacute sclerosing panencephalitis. Proc Natl Acad Sci USA 1973;70:1060-1063. 